\title{
Subtotal Gastrectomy
}

National Cancer Institute

\section{Source}

National Cancer Institute. Subtotal Gastrectomy. NCI Thesaurus. Code C51583.

Surgical removal of part of the stomach. 